\title{
Formação continuada de professores inseridos em contextos educacionais inclusivos ${ }^{1}$
}

\section{Continuing education of teachers inserted in inclusive educational contexts}

\author{
Gilmar de Carvalho Cruz $^{2}$ \\ Marisa Schneckenberg ${ }^{3}$ \\ Khaled Omar Mohamad El Tassa ${ }^{4}$ \\ LetíciaChaves $^{5}$
}

\begin{abstract}
RESUMO
O estudo objetivou: a) compreender como professoras lidam com a proposta de inclusão escolar de alunos que apresentam necessidades especiais no contexto da Educação Física; b) analisar o processo de implementação de um programa de formação continuada junto a essas professoras. Participaram vinte professoras da rede municipal de ensino de uma cidade paranaense. Foram realizadas entrevistas coletivas e observações de aulas ministradas pelas participantes. Os resultados encontrados indicam que: a) a despeito de suas formações iniciais, as professoras elaboram alternativas de intervenção favoráveis à inclusão escolar; b) professores devem assumir a condição de protagonistas em programas de formação continuada.
\end{abstract}

Palavras-chave: inclusão escolar; formação continuada; políticas educacionais.

${ }^{1}$ Apoio da Secretaria da Ciência, Tecnologia e Ensino Superior do Estado do Paraná (SETI).

${ }^{2}$ Dr. Professor da Universidade Estadual do Centro-Oeste (UNICENTRO) e do Mestrado em Educação da Universidade Estadual de Ponta Grossa (UEPG), Brasil. e-mail: gilmar@irati.unicentro. br

${ }^{3}$ Dra. Professora da Universidade Estadual do Centro-Oeste (UNICENTRO), Brasil. e-mail: marisas@irati.unicentro.br

${ }^{4}$ Mestre Professor da Universidade Estadual do Centro-Oeste (UNICENTRO), Brasil. e-mail: khaled@irati.unicentro.br

${ }^{5}$ Tutora do Curso de Pedagogia da Universidade Aberta do Brasil (UAB) da Universidade Estadual do Centro-Oeste (UNICENTRO), Brasil. e-mail: leticiachaves2009@gmail.com 


\begin{abstract}
This study focused on: a) understanding how teachers deal with the proposal of school inclusion of students with special needs in the Physical Education context; b) analyzing the implementation process of a continuing education program together with these teachers. Twenty teachers from the municipal teaching network of a city in the State of Paraná took part in this research. Group interviews and observations of classes taught by the participants were carried out. Results show that: a) in spite of their initial education, the teachers work out intervention alternatives in favor of school inclusion; b) teachers must accept the condition of protagonists in continuing education programs.
\end{abstract}

Keywords: school inclusion; continuing education; educational policies.

\title{
Introdução
}

Discussões e proposições acerca de políticas educacionais relacionadas à escolarização de pessoas que apresentam necessidades especiais estão acontecendo em níveis municipal, estadual, federal e mundial. O debate em torno dessa questão aponta para a definição de políticas educacionais inclusivas, isto é, orientadas para o atendimento de alunos com necessidades especiais em ambientes regulares de ensino. A questão da formação profissional inicial e/ou continuada encontra-se com frequência nessas discussões - quer sejam mais acadêmicas, profissionais ou políticas - que se referem à inclusão escolar de pessoas com necessidades especiais (BRASIL, 2003, 2008, 2009; MENDES, 2006; MICHELS, 2006). Neste sentido, os debates acadêmicos que dão suporte aos professores inseridos na Educação Básica precisam ser aprimorados e devem estar mais próximos das questões vivenciadas no dia a dia de intervenções profissionais relacionadas a pessoas que apresentam necessidades especiais.

A questão da formação profissional ocupa posição de destaque em debates acadêmicos, profissionais e políticos que se referem à inclusão escolar de pessoas com necessidades especiais. Importa pôr em relevo o que pode se chamar de raro consenso acerca da inclusão escolar de pessoas com necessidades especiais: a necessidade de formação profissional adequada para atender demandas específicas de alunos em contextos complexos e dinâmicos como uma sala ou quadra de aula. Em boa parte das discussões e textos elaborados sobre inclusão escolar de pessoas com necessidades especiais, a formação dos professores é invocada. Cumpre, entretanto, perceber que essa preparação profissional não encerra ao final de um curso de graduação. Muito menos se 
deve ter em mente que a pós-graduação (seja em nível lato ou stricto) será redentora de uma formação lacunar, assim como a experiência profissional, por si só, não o fará. Deste modo, convém destacar a noção de graduação como uma preparação profissional formal inicial - em contínuo processo ao longo da vida - que não pode negligenciar a constante aproximação de estudos e experiências mais recentes.

Neste sentido, Sage (1999) sinaliza que a inclusão escolar de alunos que apresentam necessidades especiais implica necessariamente em mudanças no sistema de ensino e menciona a prática reflexiva como aspecto importante de ser considerado quanto à consecução dos resultados almejados pela escola. Ideia esta que é corroborada por Mittler (2003, p. 184) ao afirmar que, do ponto de vista do desenvolvimento profissional do professor, "criar oportunidades para reflexão e discussão é essencial na implementação de qualquer tipo de inovação". Tardif (2000), por sua vez, é um dos autores para quem os conhecimentos acadêmicos e profissionais devem se articular com vistas à formação do professor, rumo ao estreitamento da relação entre professores do ensino básico e do ensino superior. Nessa mesma linha de pensamento, Schön (1997, 2000), ao elucidar-nos sobre a prática reflexiva na formação de professores - reflexão na e sobre a prática -, aponta como obstáculo para sua implementação a desarticulação promovida na universidade entre o conhecimento científico e sua aplicabilidade na prática cotidiana. Como contraponto a esta constatação, o dia a dia do professor deve ser percebido como palco para o desenvolvimento de um tipo de conhecimento pouco explorado em nível acadêmico.

À luz de seu envolvimento em programas de formação de professores do ensino básico - com ênfase no espaço ocupado pela prática pedagógica na formação inicial do professor, sem perder de vista seu aporte à formação continuada -, Zeichner (1997) alerta para limitações de práticas pedagógicas orientadas na ótica da prática reflexiva. Para ele, esta prática pode significar "um perigo, já que pode conduzir à perpetuação de um modelo conhecido de mudança em que tudo continua na mesma [...], em que as reformas servem justamente para legitimar as práticas que deveriam ser transformadas" (ZEICHNER, 1997, p. 127).

Pode-se reunir à consideração anterior as reflexões de Alarcão (2000a, 2000b) a respeito da formação reflexiva de professores. Para ela, essa "coqueluche" crescente em torno das ideias propaladas por Schön faz sentido se considerarmos, entre outros aspectos, anseios por uma formação profissional superadora da dicotomia teoria X prática. No entanto, de acordo com a mesma autora, é preciso estar alerta para que o caráter reflexivo na formação de pro- 
fessores não se reduza a reivindicações que os situem à margem das necessárias transformações educacionais. Ela prossegue seu raciocínio destacando que "educar para a autonomia implica fazer um ensino reflexivo que, por sua vez, se baseia numa postura reflexiva do próprio professor" (ALARCÃO, 2000b, p. 187).

A formação continuada do professor é abordada, na esfera da educação escolarizada, por trabalhos como os de Perrenoud (1998, 1999, 2002), que, ao enfatizar a prática reflexiva no processo de formação do professor, justifica-a devido a uma formação inicial, por vezes superficial, que pode se beneficiar da cooperação entre pares. Nessa mesma linha de pensamento, ele indica como uma das competências do professor a gestão de sua formação contínua, indicando a implementação de projetos de formação em conjunto com professores da unidade escolar. Em sua opinião, a formação contínua representa a busca de equilíbrio entre o autoritarismo das "reciclagens obrigatórias" e a desarticulação entre a liberdade de escolha dos professores quanto ao seu aperfeiçoamento e uma determinada política educacional.

$\mathrm{Na}$ Educação Especial, os debates em torno da formação do professor responsável pelo atendimento educacional escolarizado de alunos que apresentam necessidades especiais vão desde reuniões pedagógicas realizadas nas unidades escolares até a definição de políticas públicas de educação, passando por reflexões teóricas e proposições acadêmicas. Denari (2001) e Glat, Magalhães e Carneiro (1998) são algumas das autoras que, ao desferirem seus olhares sobre a formação/capacitação de professores em uma perspectiva educacional inclusiva, sinalizam a importância da experiência profissional cotidiana do professor em sua formação continuada.

Ferreira (1999) contribui à discussão sobre a elaboração de um projeto pedagógico para a formação de professores que atuam na Educação Especial apontando para uma formação inicial generalista - afinada com preceitos de atendimento à diversidade na educação escolarizada - devidamente articulada a uma formação continuada incumbida da formação específica do "educador especial". Nesta linha de pensamento pode-se reunir Jannuzzi (1995), ao sugerir como ponto de partida para uma escola inclusiva uma formação comum para todos os professores, reservando para cursos extracurriculares, de aperfeiçoamento ou de formação em serviço os conteúdos específicos pertinentes às demandas educacionais dos alunos que apresentam necessidades especiais.

Neste sentido, a proposta de implantação de um programa de formação continuada com foco nas professoras de hora-atividade de um determinado município paranaense sugere ser de interesse para aprofundar a compreensão sobre os modos como essas professoras lidam em suas intervenções com o conteúdo específico do componente curricular Educação Física em um contexto 
educacional que se pretende inclusivo. Deste modo, o estudo teve como objetivos: a) compreender como professoras de hora-atividade - responsáveis pelo conteúdo referente ao componente curricular Educação Física - de uma determinada rede municipal de ensino lidaram, em suas aulas, com a proposta de inclusão escolar de alunos com necessidades educacionais especiais; b) implementar um programa de formação continuada capaz de aprimorar o instrumental de professoras de hora-atividade com vistas à elaboração de respostas às provocações lançadas por uma perspectiva educacional inclusiva.

\section{Método}

Para efeito de implementação de um programa de formação continuada, constituiu-se um Grupo de Estudo/Trabalho, que foi encaminhamento de interesse à consecução dos objetivos propostos. O binômio Estudo/Trabalho concilia tanto a denominação tradicionalmente adotada quando da reunião de professores da Educação Básica para debater temas educacionais específicos (Grupo de Estudo) quanto a sugestão de uma dimensão prática implicada no enfrentamento de situações vivenciadas pelos professores em suas intervenções educacionais na escola (Trabalho). Esse ambiente de investigação, caracterizado pela constituição do Grupo de Estudo/Trabalho, deve considerar, além do espaço físico, as interações sociais que nele acontecem. Essas interações, que ocorrem de modo dinâmico e interdependente, tornam o ambiente da pesquisa deveras complexo. A necessária convivência entre reflexão e ação, sem preterir uma em relação à outra, numa perspectiva de mudança de certo aspecto da realidade, conduz a apontamentos realizados acerca da pesquisa-ação (BRUYNE; HERMAN; SCHOUTHEETE, 1982; THIOLLENT, 1986; COHEN; MANION, 1994; ANDRÉ, 1995; RECHE, 2001). Observações participantes, diários de campo e entrevistas foram instrumentos destinados à coleta de dados.

A rede municipal de ensino da cidade paranaense que serviu de palco para a presente pesquisa é composta por 31 escolas municipais com cerca de 170 alunos que apresentam necessidades especiais. Esses alunos estão distribuídos em espaços de atendimento que vão de classes especiais a classes regulares, passando pelas salas de recursos. Nas classes especiais são atendidos 36 alunos que apresentam deficiência mental ou condutas típicas. Outros 36 alunos com deficiência auditiva ou visual, incluídos em classes regulares, recebem também um atendimento específico. E 90 alunos com dificuldades de aprendizagem são atendidos em salas de recursos. Há ainda a presença de alguns alunos com deficiência física em algumas escolas municipais. Essas informações foram obtidas junto à Secretaria Municipal de Educação. 
A estruturação do sistema de ensino do município apresenta como peculiaridade a prevalência de professoras com graduação em pedagogia - em sua maioria -, responsáveis pelo desenvolvimento de conteúdos de Educação Física, Ensino Religioso e Artes. Essas professoras são denominadas professoras de hora-atividade e podem assumir a responsabilidade por um ou por todos os conteúdos mencionados. Há atualmente no município dois professores graduados em Educação Física que desempenham função de docência em duas das trinta e uma escolas municipais. Atualmente o sistema municipal de ensino conta com cerca de 50 professoras de hora-atividade, que realizam suas intervenções pedagógicas em cenário que tem como contorno uma política educacional assentada em uma perspectiva inclusiva.

As estratégias de ação apoiaram-se em situações colaborativas, nas quais os encaminhamentos de reflexões e ações foram definidos coletivamente. $\mathrm{O}$ desenvolvimento do programa, além de ter um caráter relacional, apoiou-se em vivências cotidianas das professoras. Portanto, a realização de entrevistas coletivas, filmagens de aulas ministradas pelas próprias professoras e diários de campo com anotações das professoras sobre suas aulas - para efeito de análises e discussões coletivas - configuraram um conjunto de estratégias para reunião de informações que permitiram a devida avaliação do impacto do programa de formação continuada proposto. Foram convidadas a participar do Grupo de Estudo/Trabalho, voluntariamente, professoras do Ensino Fundamental que atendam simultaneamente alunos com e sem deficiência pertencentes às 31 escolas da rede municipal de ensino. Vinte professoras participaram do programa, mas apenas serão apresentados dados das participantes presentes no dia da análise de aulas filmadas.

Ao longo dos anos de 2007 ( $2^{\circ}$ semestre) e 2008 ( $1^{\circ}$ e $2^{\circ}$ semestres) foram efetuados encontros (mensais, respeitando calendário da rede municipal de ensino) de 4 horas cada um com a realização de entrevistas coletivas registradas por intermédio de gravador digital. A transcrição e a análise das respectivas informações resultaram em quadros com o conjunto de respostas das participantes da pesquisa, organizados a partir de um tema disparador - relacionado à intervenção de professores inseridos em contextos educacionais inclusivos - para cada entrevista.

A partir de um (ou mais) tema(s) disparador(es), anunciado(s) a todas as participantes presentes em determinados encontros, o debate foi iniciado com cada participante emitindo sua opinião, podendo reconsiderá-la em função de algum comentário de outro integrante do Grupo. Procedeu-se, portanto, ao registro coletivo das falas individuais das participantes. Embora a entrevista tenha ocorrido coletivamente, sua análise foi realizada a partir do extrato 
individualizado das falas de cada participante - sem perder de vista os contextos nos quais elas ocorreram. Além das entrevistas coletivas, foram registradas por intermédio de filmagens aulas ministradas pelas professoras integrantes do Grupo (ao menos uma aula de cada professora).

Essas aulas filmadas foram observadas coletivamente por ocasião das reuniões do Grupo e analisadas individualmente com a utilização de um roteiro norteador, adaptado do proposto por Adamuz (2002). As análises das aulas filmadas gera-am quadros organizados a partir de respostas de cada participante às questões do roteiro norteador. Outro procedimento para coleta de dados foi o diário de campo reflexivo. Ele se constitui de anotações das professoras sobre suas próprias aulas, seguindo um conjunto de questões norteadoras para tais anotações.

As análises das aulas filmadas geraram quadros organizados a partir das respostas de cada participante às questões do roteiro norteador para análise $(\mathrm{O}$ que chamou sua atenção nesse trecho ou cena? Essa é uma estratégia que normalmente você usa? Qual é a estratégia que você usa nessa situação? Por intermédio dessa estratégia você tem conseguido sucesso? A que você atribui tais efeitos/sucessos ou dificuldades? Que outra estratégia você acredita que poderia ser utilizada? O que você sabe a respeito disso?). Durante as observações das aulas filmadas, ocorreram discussões a respeito de determinados aspectos das aulas observadas, ocasionando, eventualmente, uma pausa na reprodução da filmagem da aula em destaque. As filmagens das aulas foram realizadas pelos integrantes da equipe executora da pesquisa (utilizando-se uma filmadora digital), com a devida anuência de cada escola e com consentimento livre e esclarecido dos responsáveis pelos alunos.

Uma adaptação do quadro de análise proposto por Feldman (1995) serviu como instrumento para organização e posterior análise dos dados. A composição dos quadros decorrentes dos dados coletados seguiu sugestão de Goodwin e Watkinson (2000), que utilizaram um quadro de análise adaptado de Feldman (1995) para investigar programas de Educação Física inclusiva na perspectiva de alunos com deficiência. Feldman (1995) apresenta um olhar da semiótica sobre expressões mais superficiais e a estrutura subjacente que dá significado a essas manifestações. Trata-se, respectivamente, de seus significados denotativo e conotativo - termos utilizados para se referir às expressões e seus significados subjacentes. Esse quadro de análise permite a reunião de aspectos distintos de um determinado fenômeno de modo que eles façam sentido para os participantes do programa de formação continuada, tornando claras as conexões entre determinadas características culturais, além de explicitar os temas a elas relacionados. 
O quadro de análise elaborado a partir do referencial anteriormente mencionado constitui-se de três colunas. A primeira diz respeito às opiniões expressas pelos participantes a respeito de determinado assunto ou provocadas por uma pergunta específica. Essa expressão pode ser tanto oral (as entrevistas) quanto escrita (as análises das aulas filmadas e observadas coletivamente e os diários de campo reflexivos).

A segunda coluna aponta a ideia subjacente à opinião expressa por cada participante da pesquisa. Não há, conforme indicação de Feldman (1995), uma maneira certa para elaborar essa segunda coluna, senão uma busca de conexões entre significados que certamente são influenciados por elementos contextuais, assim como pelo referencial teórico utilizado ao longo do estudo. A terceira coluna identifica os temas que se relacionam aos significados atribuídos nas colunas anteriores.

\section{Apresentação dos dados e discussão}

A efetivação do Grupo de Estudo/Trabalho é um aspecto que merece destaque à medida que a participação das professoras se deu de modo voluntário. Neste sentido, foi possível observar o Grupo como um espaço que contribuiu para que a intensificação de diálogo com os pares ocorresse de modo sistematizado. O funcionamento do Grupo girou em torno de conteúdos que transitaram da prática para a prática, a despeito do interesse e necessidade sinalizados, pelo próprio Grupo, de também recorrer a conteúdos de natureza teórica.

Os quadros apresentados a seguir dizem respeito a fragmento das análises de aulas ministradas pelas professoras integrantes do Grupo. Essas aulas foram filmadas e reproduzidas nos encontros do Grupo e, para efeito da análise proposta, utilizou-se um roteiro norteador composto por sete questões abertas, adaptadas de Adamuz (2002). Serão destacadas duas questões referentes a dois contextos distintos, alvo das análises realizadas, que contaram com maior número de respondentes: a) O que chamou sua atenção nesse trecho ou cena?; b) A que você atribui tais efeitos - sucessos ou dificuldades?

As falas registradas das professoras serão demonstradas pela expressão das participantes; as professoras serão representadas pela letra $P$ e numeradas: $P 1, P 2 \ldots$ e sucessivamente, levando em consideração que algumas não se manifestaram em relação a algumas questões ou não estiveram presentes no dia do encontro realizado. 
Contexto: Aluno com paralisia cerebral incluído em turma de $2^{\mathrm{a}}$ série $02 / 04 / 2008$

\begin{tabular}{|l|c|c|}
\hline \multicolumn{1}{|c|}{ Expressão dos Participantes } & Ideia Subjacente & $\begin{array}{c}\text { Tema de } \\
\text { Focalização }\end{array}$ \\
\hline P1 Participação ativa do aluno & Organização das atividades & Intervenção profissional \\
P2 Integração & Envolvimento dos alunos & Ambiente fisicossocial \\
P3 Persistência do aluno & Socialização & Ambiente fisicossocial \\
P4 Participação contínua na aula & Atividades & Intervenção profissional \\
P5 Coordenação motora do aluno & Comportamento motor & Especificidade \\
P6 Persistência do aluno & Desempenho do aluno & Especificidade \\
P7 Participação de todos & Cooperação dos colegas & Ambiente fisicossocial \\
P8 Êxito do aluno nas atividades & Atividades compatíveis & Intervenção profissional \\
P9 Participação de todos & Organização das atividades & Intervenção profissional \\
P10 Participação do aluno & Organização das atividades & Intervenção profissional \\
P11 Coordenação motora & Desempenho do aluno & Especificidade \\
P12 Participação do aluno & Desempenho do aluno & Especificidade \\
P13 Participação do aluno & Organização das atividades & Intervenção profissional \\
P14 Estratégias do aluno & Desempenho do aluno & Especificidade \\
P15 Integração e participação & Envolvimento dos alunos & Ambiente físicossocial \\
P16 Dificuldade imperceptível & Desempenho do aluno & Especificidade \\
P17 Participação ativa do aluno & Desempenho do aluno & Especificidade \\
P18 Integração & Cooperação dos colegas & Ambiente físicossocial \\
\hline
\end{tabular}

Quadro 1 - O que chamou sua atenção nesse trecho ou cena?

De acordo com o ponto de vista de $P 1, P 3, P 4, P 5, P 6$ e P7, foi possível realizar todas as atividades propostas pela profissional. É importante ressaltar que a presença do aluno com paralisia cerebral (PC) não interferiu no andamento da aula, muito pelo contrário; o aluno, assim como os demais colegas, realizou todas as atividades propostas com entusiasmo, persistência e felicidade, demonstrando uma ótima interação com a turma.

Para $P 7$ e $P 15$, a integração do referido aluno com PC com os demais foi muito satisfatória. $\mathrm{O}$ interesse do mesmo pelas atividades reforça que o potencial do aluno deve ser desenvolvido e valorizado, tendo em vista que ele conseguiu realizar todos os movimentos propostos, demonstrando equilíbrio e coordenação motora, sendo capaz de participar efetivamente das aulas de Educação Física. De acordo com observação de $P 15$, "o aluno estava bem integrado com os colegas e estes não fizeram nenhum tipo de diferenciação quanto a sua dificuldade. E que o aluno participou de todas as atividades tentando cumprir com os objetivos". 
O desempenho do aluno na realização das atividades chamou muito a atenção dos participantes e isso prova que as limitações existem, mas podem e devem ser trabalhadas com objetividade, percebendo e ampliando vários caminhos e opções para o melhor desenvolvimento do aluno dentro das suas potencialidades.

As questões que mais chamaram a atenção dos participantes foram mais voltadas particularmente para o desenvolvimento do aluno com Paralisia Cerebral e aquelas relacionadas à integração e à intervenção profissional. Analisando o próximo quadro em contexto diferente, podemos ver que as professoras se utilizam de várias estratégias para melhorar suas aulas, com ou sem a presença de aluno incluso. $\mathrm{O}$ quadro a seguir tem como contexto um aluno da educação infantil, cadeirante, aluno incluso. $\mathrm{O}$ mesmo participa de todas as atividades com entusiasmo e felicidade. Um ponto que chamou bastante a atenção das professoras foi a expressividade no rosto da criança.

Contexto: Aluno usuário de cadeira de rodas incluído em turma de $4^{\mathrm{a}}$ série - 15/04/2008

\begin{tabular}{|l|c|c|}
\hline \multicolumn{1}{|c|}{ Expressão dos Participantes } & Idéia Subjacente & Tema de Focalização \\
\hline P1 Participação ativa da turma & Organização das atividades & Intervenção profissional \\
P2 Interação da turma & Envolvimento dos alunos & Intervenção profissional \\
P3 Satisfação & Desempenho do aluno & Especificidade \\
P4 Integração e participação & Cooperação da turma & Ambiente físicossocial \\
P5 Persistência do aluno & Desempenho do aluno & Intervenção social \\
P6 Participação ativa da turma & Organização das atividades & Intervenção profissional \\
P7 Participação ativa da turma & Organização das atividades & Intervenção profissional \\
P8 Integração e participação & Cooperação da turma & Ambiente fisicossocial \\
P9 Estratégias utilizadas pela & Organização das atividades & Intervenção profissional \\
professora & Envolvimento dos alunos & Intervenção profissional \\
P10 Interação da turma & Envolvimento dos alunos & Intervenção profissional \\
P11 Interação da turma & Desempenho do aluno & Especificidade \\
P12 Satisfação & Organização das atividades & Intervenção profissional \\
P13 Busca pela satisfação & Organização das atividades & Intervenção profissional \\
P14 Comprometimento &
\end{tabular}

Quadro 2 - A que você atribui tais efeitos - sucessos ou dificuldades?

De acordo com o ponto de vista de $P 1, P 6, P 7, P 9, P 13$ e $P 14$, foi possível realizar as atividades propostas pela professora, pois a turma cooperou para 
que as atividades pudessem ser realizadas pelo aluno usuário de cadeira de rodas, fazendo assim com que as aulas tivessem o sucesso esperado pela professora. Na opinião de $P 11$, o sucesso da aula foi devido "ao entrosamento dos alunos e aceitação (boa) das atividades propostas". Para P3, P5 e P12, o sucesso obtido com as aulas é a maior satisfação, por se poder ver o aluno com necessidades especiais realizando as atividades e a turma vivenciando com o mesmo as atividades propostas.

É mister destacar uma mudança observável de perspectiva das professoras no que se refere ao tema da inclusão escolar. Elas tendem à certeza de não conseguir atender um aluno que no campo das necessidades especiais apresenta algum tipo de deficiência, até a percepção da possibilidade de efetivamente envolver alguns alunos, com características peculiares (deficiência física, deficiência mental e visão subnormal, por exemplo), em suas aulas.

\section{Considerações finais}

A incipiente presença de professores de Educação Física não impediu que conteúdos relativos a esse componente curricular fossem desenvolvidos nas escolas. Cabe destacar que há uma Coordenação de Educação Física na Secretaria Municipal de Educação que visa dar suporte ao trabalho realizado pelas professoras de hora-atividade. Havia uma perspectiva inicial de realizar encontros quinzenais com as participantes da pesquisa, que esbarrou na organização da rede municipal de ensino, conduzindo à realização de encontros mensais em dois turnos: matutino e vespertino. Esse alongamento no período entre os encontros, contudo, foi superado por intermédio de contatos presenciais com as escolas das participantes da pesquisa a fim de preparar o terreno para filmagens de suas aulas.

Foi possível acompanhar, junto às participantes da pesquisa, que questões específicas relacionadas às peculiaridades de alunos que no âmbito das necessidades especiais apresentam algum tipo de deficiência não se fizeram presentes desgarradas das dificuldades enfrentadas para atender alunos que não apresentam deficiência. Isso indica que as condições peculiares do processo ensino-aprendizagem em um contexto educacional pretensamente inclusivo não podem perder de vista questões gerais, de fundo, que interferem no referido processo.

Os processos de formação profissional das participantes da pesquisa sugerem não ter contribuído para que as mesmas se sentissem preparadas para atuar em um contexto educacional inclusivo. A superação dessa situação passa pelo incremento de programas de formação continuada com características mais 
relacionais, conforme desenvolvido neste estudo, que colocam os profissionais da Educação Básica na condição de autores de intervenções educacionais capazes de contribuir no enfrentamento dos desafios impostos por um cenário educacional inclusivo. Cabe destacar, como uma das características do programa de formação continuada proposto, a sua exequibilidade do ponto de vista operacional e financeiro.

Cabe sinalizar que a aproximação dos modos como as participantes da pesquisa lidam com o atendimento simultâneo de alunos com e sem necessidades especiais em suas aulas aponta para uma contradição de interesse ao trabalho proposto. A despeito de suas falas e percepções iniciais sobre o assunto, é possível observá-las promovendo a efetiva participação de alunos com necessidades especiais em suas aulas, apoiadas em conteúdos da Educação Física. Essa observação permite que se avance no sentido da proposição de um programa de formação de professoras do Ensino Fundamental para intervirem em ambientes escolares inseridos em contextos educacionais inclusivos.

Cabe destacar no desenvolvimento do programa de formação continuada o efetivo envolvimento das professoras como protagonistas das reflexões realizadas, a fim de que as mesmas fossem ao encontro de suas demandas profissionais cotidianas. Esse destaque é necessário pelo fato de que não raro os programas de formação continuada de professores da rede básica traduzem propostas não dialogadas com as demandas mais específicas de uma determinada rede ou delegacia/núcleo de ensino. Neste sentido, a participação voluntária das professoras foi fator fundamental à constituição e consolidação do Grupo.

A respeito do processo de formação vivenciado pelo Grupo, o conteúdo prático das discussões merece ser evidenciado. A contradição presente na procura de formação/informação garantidora da intervenção profissional almejada se manifestou na reivindicação, em alguns momentos, de conhecimento teórico e, noutros, de experiências reveladoras de um conhecimento prático que se mostrasse capaz de atender a anseios mais imediatos. A busca do desenvolvimento profissional, apoiado numa perspectiva de autoaprimoramento com vistas a intervenções de impacto diante das demandas sociais existentes, sugere ser um aspecto central na ampliação do entendimento de formação continuada.

\section{REFERÊNCIAS}

ADAMUZ, R.C. A reinterpretação da prática pedagógica por um professor com uma aluna com deficiência mental inserida no ensino comum. $141 \mathrm{f}$. Tese (Doutorado em Educação) - Universidade Estadual Paulista. Marília, SP, 2002. 
ALARCÃO, I. Reflexão crítica sobre o pensamento de D. Schön e os programas de formação de professores. In: ALARCÃO, I. (Org.). Formação reflexiva de professores: estratégias de supervisão. Porto: Porto Editora, 2000a. p. 9-39.

. Ser professor reflexivo. In: ALARCÃO, I. (Org.). Formação reflexiva de professores: estratégias de supervisão. Porto: Porto Editora, 2000b. p. 171189.

ANDRÉ, M. E. D. A. Etnografia da prática escolar. Campinas: Papirus, 1995.

BRASIL. Diretrizes Nacionais para a Educação Especial na Educação Básica. Disponível em: <http://www.mec.gov.br/seesp/legislacao.shtm>. Acesso em: 04/04/2003.

. Política Nacional de Educação Especial na Perspectiva da Educação Inclusiva (Documento elaborado pelo Grupo de Trabalho nomeado pela Portaria $n^{\circ} 555 / 2007$, prorrogada pela Portaria $n^{\circ}$ 948/2007, entregue ao Ministro da Educação em 07 de janeiro de 2008). Ministério da Educação. Brasília, 2008.

. Decreto $n^{0} 6.755$, de 29 de janeiro de 2009. Institui a Política Nacional de Formação de Profissionais do Magistério da Educação Básica. Brasília: DOU, 30 de janeiro de 2009.

BRUYNE, P.; HERMAN, J.; SCHOUTHEETE, M. Dinâmica da pesquisa em Ciências Sociais. 2. ed. Rio de Janeiro: F. Alves, 1982.

BUENO, J. G. S. Crianças com necessidades educativas especiais, política educacional e a formação de professores: generalistas ou especialistas? Revista Brasileira de Educação Especial, Piracicaba, v. 3, n. 5, p. 7-25, 1999.

COHEN, L.; MANION, L. Research methods in Education. 4. ed. London: Routledge, 1994.

DENARI, F. E. A escola perante as diferenças: um olhar sobre a formação do professor. In: MARQUEZINE, M. C.; ALMEIDA, M. A.; TANAKA, E. D. O. (Org.). Perspectivas Multidisciplinares em Educação Especial II. Londrina: Ed. UEL, 2001. p. 177-181.

FELDMAN, M. S. Strategies for interpreting qualitative data. Thousand Oaks, California: Sage Publications, 1995. 
FERREIRA, J. R.; SOUZA, M. I.; NUNES, L. R. O. P.; MENDES, E. G.; GLAT, R. Teses e dissertações de educação e psicologia: formação de recursos humanos para a educação especial. Temas em psicologia da SBP, Ribeirão Preto, v. 10, n. 3, p. 249-259, 2002.

FERREIRA, M. C. C. Construindo um projeto político-pedagógico para a formação de educadores no contexto da educação especial. In: BICUDO, M. A. V.; SILVA Jr., C. A. Formação do educador e avaliação educacional: formação inicial e continuada. São Paulo: UNESP, 1999. p. 139-148.

GLAT, R.; MAGALHÃES, E. F. C. B.; CARNEIRO, R. Capacitação de professores: primeiro passo para uma educação inclusiva. In: MARQUEZINE, M. C.; ALMEIDA, M. A.; TANAKA, E. D. O.; MORI, N. N. R.; SHIMAZAKI, E. M. (Orgs.). Perspectivas Multidisciplinares em Educação Especial. Londrina: Ed. UEL, 1998. p. 373-378.

GOODWIN, D. L.; WATKINSON, E. J. Inclusive physical education from the perspective of students with physical disabilities. Adapted Physical Activity Quarterly, Champaign, v. 17, p. 144-160, 2000.

JANNUZZI, G. S. M. Políticas públicas e a formação do professor. In: CICLO DE DEBATES EM EDUCAÇÃO ESPECIAL, 1., 1995, Campinas. Anais... Campinas: UNICAMP-FE, 1995. p. 1-10.

MENDES, E. G. A radicalização do debate sobre inclusão escolar no Brasil. Revista Brasileira de Educação, v. 11, n. 33, p. 387-405, set./dez. 2006.

MICHELS, M. H. Gestão, formação docente e inclusão: eixos da reforma educacional brasileira que atribuem contornos à organização escolar. Revista Brasileira de Educação, v. 11, n. 33, p. 406-423, set./dez. 2006.

MITTLER, P. Educação inclusiva: contextos sociais. Porto Alegre: Artmed, 2003.

PERRENOUD, P. Formar professores em contextos sociais em mudança: prática reflexiva e participação crítica. Revista Brasileira de Educação, Campinas, n. 12, p. 5-21, set./dez. 1999.

. A prática reflexiva no oficio de professor: profissionalização e razão pedagógica. Porto Alegre: Artmed, 2002. 
. Formação contínua e obrigatoriedade da competência na profissão de professor. In: CONHOLATO, M. C. (Coord.). Sistemas de Avaliação Educacional. São Paulo: FDE, 1998. p. 205-248.

RECHE, C. C. Aplicabilidade dos resultados de pesquisa em sala de aula. In: NUNES, F. P.; NAUJORKS, M. I. (Org.). Pesquisa em Educação Especial: o desafio da qualificação. Bauru: EDUSC, 2001. p. 91-105.

SAGE, D. D. Estratégias administrativas para a realização do ensino inclusivo. In: STAINBACK, S.; STAINBACK, W. Inclusão: um guia para educadores. Porto Alegre: Artes Médicas Sul, 1999. p. 129-141.

SCHÖN, D. Formar professores como profissionais reflexivos. In: NÓVOA, A. (Org.). Os professores e a sua formação. 3. ed. Lisboa: Publicações Dom Quixote, 1997.

. Educando o profissional reflexivo: um novo design para o ensino e a aprendizagem. Porto Alegre: Artes Médicas Sul, 2000.

TARDIF, M. Saberes profissionais dos professores e conhecimentos universitários: elementos para uma epistemologia da prática profissional dos professores e suas consequências em relação à formação para o magistério. Revista Brasileira de Educação, Campinas, n. 13, p. 5-24, jan./abr. 2000.

THIOLlENT, M. Metodologia da pesquisa-ação. 3. ed. São Paulo: Cortez, 1986.

ZEICHNER, K. Novos caminhos para o practicum: uma perspectiva para os anos 90. In: NÓVOA, A. (Org.). Os professores e a sua formação. 3. ed. Lisboa: Publicações Dom Quixote, 1997. p. 115-138.

Texto recebido em 11 de março de 2010.

Texto aprovado em 23 de maio de 2010. 
